Bangladesh J. Zool. 41(2): 241-246, 2013

\title{
DIAGNOSIS OF IMPORTED MALARIA IN JAPAN BY USING MICROTITER PLATE-HYBRIDIZATION TECHNIQUE
}

\author{
Tangin Akter \\ Department of Zoology, University of Dhaka, Dhaka-1000, Bangladesh
}

\begin{abstract}
In Japan, malaria has been successfully eradicated but imported malaria is still a great problem. Blood samples of malaria patients were collected from different hospitals of Japan. The samples were diagnosed by PCR based Microtiter plate-hybridization technique (MPH). The results of MPH were compared with microscopic diagnosis done at the laboratories of different hospitals. Among the total 23 blood samples examined, 19 were diagnosed as malaria parasite positive by $\mathrm{MPH}$ technique. The malaria parasites found were Plasmodium falciparum 7 (36.7\%), Plasmodium vivax 6 (31.6\%), Plasmodium ovale 1 (5.3\%), Plasmodium ovale variant 3 (15.8\%), Plasmodium malariae 1 (5.3\%). One mixed infection of $P$. falciparum and $P$. ovale $(5.3 \%)$ were also recorded. The area of acquisition of malaria was highest from Africa followed by Oceania, Asia, South America and others. This investigation indicated the MPH technique was more specific than microscopy for the diagnosis of imported malaria.
\end{abstract}

Key words: Microtiter plate -hybridization, Malaria parasite, Japan.

\section{INTRODUCTION}

In Japan, parasitic diseases have been successfully controlled specially indigenous malaria was eradicated in 1961. However, during the last decade the development of tourism and travel caused an increase of malaria cases in migrants and travelers returning from the malaria endemic areas (Rougemont et al. 2004). In 2000, seven million Japanese travelers visited malaria endemic area (Kimura et al. 2003). Increasing number of Japanese has been traveling to malaria endemic countries for business and vacation and people from countries with malaria endemicity has also been visiting in Japan for education. Kano and Kimura (2004) reported that this kind of global travel has resulted 100-160 cases of imported malaria per year in Japan.

The diagnosis of malaria has traditionally been relied on the microscopic examination of Giemsa-stained blood smears. In Japan, microscopic identification of malaria parasites is not sufficient specially in the case of low level parasitemia and mixed infection (Snounou et al. 1993; Scopel et al. 2004; Kimura et al. 1995). Therefore, it has been found that the fatalities among the malarial patients in Japan are higher than that in other developed countries. This is because of the lack of prompt and proper diagnosis and treatment not provided by the physician (Kano and Kimura (2004). The aim of this study was to utilize the quick Microtiter Plate-Hybridization (MPH) technique for malarial 
parasite identification in human blood and compare the results with microscopic observations.

\section{MATERIAL AND METHODS}

The experiment was conducted at the laboratory of Department of drug and informatics, University of Okayama, Japan. Blood samples of malaria patients were received from different hospitals of Japan. For parasite extraction, $10 \mu \mathrm{L}$ blood sample from each malaria patient and fresh non-infected blood as control were suspended in $150 \mu \mathrm{l}$ of phosphate-buffered saline (PBS) containing 10 $\mathrm{U} / \mathrm{ml}$ of Nystatin and $25 \mu \mathrm{g} / \mathrm{ml}$ of Gentamycin in separate $0.5 \mathrm{~mL}$ tube. The samples were hemolyzed by adding $18 \mu 1$ of $0.2 \%$ Saponin/PBS (final concentration of about $0.02 \%$ ), which was then incubated at room temperature for about 5 minutes. The mixture was centrifuged at 10,000 rpm for 10 minutes. Then the supernatant was discarded. The pellet was re-suspend with $200 \mu \mathrm{L}$ PBS, vortexed and centrifuged at $10,000 \mathrm{rpm}$ for 10 minutes. The supernatant was discarded and added $40 \mu \mathrm{l}$ of lysis solution. Then the sample was incubated at $60^{\circ} \mathrm{C}$ for 20 minutes for destruction and proteolysis, $95^{\circ} \mathrm{C}$ for 13 minutes to inactivate the Proteinase $\mathrm{K}$ and was cooled at $50^{\circ} \mathrm{C}$ for 5 minutes.

The sequences of the oligonuleotide primer set, 5'-CAGATACCGTCGTAAT CTTA-3'and 5'-CCAAAGACTTTGATTTCTCAT-3' used have been described elsewhere (Arai et al. 1994; Kimura et al. 1995). The sample was spun down and mixed with $10 \mu \mathrm{L}$ of PCR reagent mixture. The mixture was subjected to 30 cycles. The conditions were as follows: denaturation at $92^{\circ} \mathrm{C}$ for $60 \mathrm{sec}$, annealing at $52^{\circ} \mathrm{C}$ for $90 \mathrm{sec}$, extension at $72^{\circ} \mathrm{C}$ for $90 \mathrm{sec}$. The amplified DNA was denatured by heating at $95^{\circ} \mathrm{C}$ for 10 minutes and then rapid cooling on ice for 10 minutes. Positive control was used as DNA of five malaria parasites from clinical patients. Sterilized water was used for negative control. $10 \mu \mathrm{L}$ of the PCR products were electrophoresed at 100v for 40 minutes using $1.2 \%$ agarose gel.

The procedure of hybridization and colorization of MPH technique have previously described (Arai et al. 1996; Kimura et al. 1995). In briefly, microtiter plate wells are coated with probes specific for $P$. falciparum, $P$. vivax, $P$. ovale, and $P$. ovale-variant and $P$. malariae was filled with $100 \mu \mathrm{L} /$ well of $5 \mathrm{x}$ SSC $(1 \mathrm{x}$ SSC is $0.15 \mathrm{M} \mathrm{NaCl}$ plus $0.015 \mathrm{M}$ sodium citrate) and $5 \mu \mathrm{L}$ PCR product was added in the wells. Then the plate was incubated at $58^{\circ} \mathrm{C}$ for 1 hour and after that the solution was removed and the wells were washed three times by $250 \mu \mathrm{L} /$ well of $1 \mathrm{x}$ solution $\left(0.1 \mathrm{M}\right.$ Tris- $\mathrm{HCl}(\mathrm{pH} 7.5), 0.1 \mathrm{M} \mathrm{NaCl}, 2 \mathrm{mM} \mathrm{MgCl}_{2}$, $0.05 \%$ TritonX-100).Then added $100 \mu \mathrm{L}$ of alkaline phosphatase labeled streptavidin and incubated at $28^{\circ} \mathrm{C}$ for 15 minutes. After that the solution was removed and the well was washed three times by $250 \mu \mathrm{L} /$ well of $1 \mathrm{x}$ solution. 
Then added $100 \mu \mathrm{L} /$ well coloring substrate, PNPP solution (1M diethanolamine (pH 9.8), $0.5 \mathrm{mM} \mathrm{MgCl}_{2}$, and $10 \mathrm{mM}$ Para-nitrophenyl phosphate) and was incubated at $28^{\circ} \mathrm{C}$ for 30 minutes. The absorbance of each well was read at $405 \mathrm{~nm}$ by using a microtiter plate reader (MPR-A4, Tosoh, Tokyo, Japan). The data were obtained by observing the blank and 30 minutes absorbance value of the background corresponding to the PNPP solution. All confirmed cases of malaria which were received since 2004-2007 were revised by different parameters such as year, age, sex, nationality, area of infection, Plasmodium species.

\section{RESULTS AND DISCUSSION}

Blood samples from 23 malaria patients were received from different hospitals of Japan since 2004 to 2007 . All the blood samples were diagnosed by MPH technique. Among the 23 patients, 19 were positive for malaria parasite. Among these, 11 were Japanese, 7 were foreigners and the rest 1 was unknown citizenship. The most frequent areas for acquisition of malaria were Africa, followed by Oceania, Asia and South America (Table 1).

Table 1. Citizenship, their foreign visits and diagnosis of the malaria patients at Japan hospitals

\begin{tabular}{|c|c|c|c|c|c|}
\hline Citizen & Country visit & $30 \mathrm{~min}$. & Blank & MPH & Microscopy \\
\hline Japanese & Amazon, Brazil & 0.792 & 0.168 & P. v. (+) & $(-)$ \\
\hline Japanese & Papua New Guinea & 0.429 & 0.168 & P. v. $(+)$ & P. v. $(+)$ \\
\hline Japanese & Papua New Guinea & 0.611 & 0.149 & P. v. $(+)$ & P. v. $(+)$ \\
\hline Japanese & Burkina Faso & 0.972 & 0.117 & P. o. $(+)$ & P. o. $(+)$ \\
\hline Japanese & Indonesia & 0.318 & 0.136 & P. v. (+) & P. $f(+)$ \\
\hline Japanese & Kenya & 0.571 & 0.105 & P.f. $(+)$ & P. $f .(+)$ \\
\hline Japanese & Kenya & 1.822 & 0.123 & P. $f .(+)$ & $P . f .(+)$ \\
\hline Japanese & Salmon Island & 0.393 & 0.118 & P. v. $(+)$ & None \\
\hline Japanese & Ghana & 1.453 & 0.129 & $P . f .(+)$ & $P . f .(+)$ \\
\hline Japanese & Sierra Leone & 0.460 & 0.123 & $P . f .(+)$ & P. $f .(+)$ or mixed \\
\hline Japanese & Burkina Faso & 1.800 & 0.168 & P. $f .(+)$ & P. v. or P. m. $\left(^{+}\right)$ \\
\hline $\begin{array}{l}\text { Papua New } \\
\text { Guinea }\end{array}$ & Papua New Guinea & 1.615 & 0.124 & P. m. $\left(^{+}\right)$ & None \\
\hline Ethiopia & Ethiopia & 0.925 & 0.122 & P. v. $(+)$ & P. v. $(+)$ \\
\hline Ghana & Ghana & 1.803 & 0.168 & $P . f .(+)$ & $P . f .(+)$ \\
\hline Cameroon & Cameroon & 0.997 & 0.145 & P. $o-v(+)$ & \\
\hline Cameroon & Cameroon & 1.431 & 0.145 & P. o- $v .(+)$ & P. о. $(+)$ \\
\hline Cameroon & Cameroon & 1.683 & 0.104 & P.f. $(+)$ & $(-)$ \\
\hline Nigeria & Nigeria & 0.568 & 0.168 & P. f. and P.o. $\left(^{+}\right)$ & $\begin{array}{l}P . f .(+) \text { and } \\
\text { unknown }\end{array}$ \\
\hline Unknown & Unknown & 1.487 & 0.135 & P. o- $v .(+)$ & P. о. $(+)$ \\
\hline
\end{tabular}

P.f. $=$ Plasmodium falciparum, P.v. = Plasmodium vivax, P.o. $=$ Plasmodium ovale, P.o-v $=$ Plasmodium ovale-vivax, P.m. = Plasmodium malariae 
The number of malaria parasite positive cases were $7(36.7 \%)$ with $P$. falciparum, $6(31.6 \%)$ with $P$. vivax, $1(5.3 \%)$ with $P$. ovale, $3(15.8 \%)$ with $P$. ovale variant, $1(5.3 \%)$ with $P$. malariae and $1(5.3 \%)$ with mixed infection of $P$. falciparum and $P$. ovale. In this study two microscopy negative samples were diagnosed as malarial parasite positive ( $P$. vivax, $P$. falciparum) by MPH. During the present study, three samples were identified as $P$. ovale variant positive by MPH technique. But during the microscopic studies, two of the samples were identified as $P$. ovale positive and 1 as unknown. Among these three patients, two were from the same family (Table 2).

Table 2. Microtiter plate hybridization (MPH) results of the malaria patients from different hospitals of Japan

\begin{tabular}{|c|c|c|c|c|c|c|}
\hline \multirow[t]{2}{*}{ Citizen } & \multicolumn{5}{|c|}{$\begin{array}{l}\text { Micrititer Plate Hybridization (Absorbance value at } 405 \mathrm{~nm} \text { ) } \\
\text { results }\end{array}$} & \multirow[t]{2}{*}{ Remarks } \\
\hline & P.f. & P.v. & $P . o$ & P.o-v. & P.m. & \\
\hline $\begin{array}{l}\text { Papua New } \\
\text { Guinea }\end{array}$ & 0.000 & 0.000 & 0.000 & 0.016 & 1.615 & P.m. \\
\hline Ethiopia & 0.006 & 0.925 & 0.022 & 0.022 & 0.033 & P.v. \\
\hline Japanese & 1.800 & 0.018 & 0.009 & 0.029 & 0.025 & p.f. \\
\hline Ghana & 1.803 & 0.000 & 0.000 & 0.000 & 0.000 & P.f. \\
\hline Cameroon & 0.000 & 0.000 & 0.000 & 0.997 & 0.000 & P.o-v. \\
\hline Cameroon & 0.000 & 0.003 & 0.006 & 1.431 & 0.000 & P.o-v. \\
\hline Japanese & 0.460 & 0.000 & 0.003 & 0.010 & 0.009 & P.f. \\
\hline Cameroon & 1.683 & 0.000 & 0.000 & 0.000 & 0.006 & P.f. \\
\hline Unknown & 0.000 & 0.000 & 0.000 & 1.487 & 0.000 & P.o-v. \\
\hline Nigeria & 1.453 & 0.000 & 0.508 & 0.024 & 0.000 & $\begin{array}{l}\text { P.f. and } \\
\text { P.o. }\end{array}$ \\
\hline Japanese & 0.000 & 0.568 & 0.000 & 0.997 & 0.000 & P.v. \\
\hline Japanese & 0.000 & 0.792 & 0.000 & 0.000 & 0.000 & P.v. \\
\hline Japanese & 0.000 & 0.429 & 0.000 & 0.000 & 0.004 & P.v. \\
\hline Japanese & 0.611 & 0.000 & 0.000 & 0.000 & 0.025 & P.f. \\
\hline Japanese & 0.009 & 0.032 & 0.056 & 0.049 & 0.070 & - \\
\hline Japanese & 0.000 & 0.000 & 0.972 & 0.000 & 0.000 & P.o. \\
\hline Japanese & 0.000 & 0.318 & 0.000 & 0.000 & 0.007 & P.v. \\
\hline Japanese & 0.571 & 0.043 & 0.096 & 0.035 & 0.046 & P.f. \\
\hline Japanese & 1.822 & 0.031 & 0.093 & 0.056 & 0.062 & P.f. \\
\hline Japanese & 0.000 & 0.000 & 0.012 & 0.018 & 0.000 & - \\
\hline Japanese & 0.007 & 0.000 & 0.008 & 0.009 & 0.009 & - \\
\hline Japanese & 0.000 & 0.393 & 0.000 & 0.000 & 0.000 & P.v. \\
\hline Japanese & 0.000 & 0.000 & 0.014 & 0.018 & 0.017 & - \\
\hline
\end{tabular}

P.f.=Plasmodium falciparum, P.v.= Plasmodium vivax, P.o.= Plasmodium ovale, P.o-v.= Plasmodium ovale-vivax, P.m. = Plasmodium malariae.

In this study, the most predominant Plasmodium species was P. falciparum (36.7\%). In Japan P. falciparum has always been a leading species with a ratio of $50 \%$ cases observed by Kimura et al. (2005), 45\% reported by Kano and Kimura 
2004, and 31\% reported by Wataya et al. (1998). Only one P. malariae patient was diagnosed among 19 malarial patient. Yagita and Endo (1999) also reported rare occasions of $P$. malariae in Japan.

Microscopy is the traditional method for the diagnosis of malaria caused by Plasmodium species. However, the accurate species identification may be difficult for all patients as seen in the present work. Rubio et al. (1999) described the potential usefulness of PCR diagnosis of 192 suspected malarial patients in Spin. They observed that PCR detected positive malaria specimens in 30 samples which was negative in microscopy and also identified mixed infection in additional six samples. In another study it was also found that the diagnosis by microscopy is problematic in patient with mixed infection (Brown et al. 1992). The same result was observed in this study in case of mixed infection detected by MPH which was not detected by microscopy. Therefore, it was evident that PCR method is very much useful in detection of mixed infection, which is sometimes overlooked microscopically.

In the developed countries where malaria has already been controlled, the imported malaria will be more risk as the international travelers are increasing day by day. Therefore, the malaria diagnosis technique should have to be specific, proper and fast. This is because the treatment of malaria is depended upon the malaria species (Ohnishi and Murata, 1996). From the present study it was confirmed that most of the patients got infection from African countries and MPH technique was more specific in diagnosis.

Acknowledgements: The author is grateful to Professor Yusuke Wataya, Professor Hye-Sook Kim, University of Okayama, Japan for their guidance and support. Author is also grateful to all members of the laboratory of Department of drug and informatics, University of Okayama, Japan and Government of Japan for providing a grant of Monobukagakusho for financial support.

\section{LITERATURE CITED}

ARAI, M., KUNISADA, K., KAWAI, S., KIMURA, M. and WATAYA, Y. 1994. DNA diagnosis of ovale malaria and malariae malaria using microtiter plate-hybridization. Nucleosides. Nucleotides. 13: 1363-1374.

BROWN, A.E., KAIN K.C., PIPITHKUL, J. and WEBSTER, H.K. 1992. Demonstration by the polymerase chain reaction of mixed Plasmodium falciparum and Plasmodium vivax infections undetected by conventional microscopy. Trans. R. Soc. Trop. Med. Hyg. 86: 609-612.

FUKUMI N-U., KENJI H., KENJI I., YUKIKO S. and YUKIFUMI N. 2003. The current status of parasitic diseases in Japan. Internal. Medicine. 42(3): 222-236.

KANO, S. and KIMURA, M. 2004. Trends in malaria cases in Japan. Acta. Trop. 89(3): 271-278. 
KIMURA, M., MIYAKO, H., KIM, H-S., TANABE, M., ARAI, M., KAWAI, S., YAMANE, A. and WATAYA, Y. 1995. Species-specific PCR detection of malaria parasites by Microtiter Plate Hybridization: Clinical study with malaria patients. J. Clin. Microbiol. 33(9): 2342-2346.

KIMURA, M., SUZUKI, A., MATSUMOTO, Y., NAKAJIMA, K., WATAYA, Y. and OHMOTO, H. 2003. Epidemiological and clinical aspects of malaria in Japan. J. Travel. Med. 10(2):122-127.

KIMURA, T., KIMURA, M., and KOIBUCHI, T. 2005. Clinical characteristics of imported malaria in Japan: Analysis at referral hospital. Am. J. Trop. Med. Hyg. 73(3): 599-603.

OHNISHI, K. and MURATA, M. 1996. Malaria-eight years experiences in a Tokyo Metropolitan hospital. Intern. Med. 35(2):111-114.

ROUGEMONT, M., VAN, S.M., SAHLI, R., HINRIKSON, H.P., BILlE, J. and JATON, K. 2004. Detection of four Plasmodium species in blood from humans by $18 \mathrm{~S}$ rRNA gene subunit-based and species-specific real time PCR assays. J. Clinic. Microbiol. 42(12): 5636-5643.

RUBIO, J.M., BENTIO, A., BERZOSA, P.J., ROCHE, J., PUENTE, S., SUBIRATS, M., LOPEZ-VELEZ R., GERCIA, L. and ALVAR, J. 1999. Usefulness of semi-nested multiplex PCR surveillance of imported malaria in Spain. J. Clinic. Microiol. 37: 3260-3264.

SCOPEL, K.K., FONTES, C.J., NUNES, A.C., HORTA, M.F. and BRAGA, E.M. 2004. High prevalence of Plasmodium malariae infections in a Brazilian Amazon endemic area (Apicas-Mato Grosso State) as detected by Polymerase Chain reaction. Acta. Trop. 90(1): 61-64.

SNOUNOU, G., VIRIYAKOSOL, S., THAITHONG, S., JARRA, W. and BROWN, K.N. 1993. Identification of the four human malaria parasite species in field samples by the polymerase chain reaction and detection of high prevalence of mixed infections. Mol. Biochem. Parasitol. 58(2): 283-292.

WATAYA, Y., MIYAKO, H. and KIM, H-S. 1998. Usefulness of a new DNA diagnostic method for malaria; microtiter plate hybridization. Tokai. J. Exp. Clin. Med. 23(2): 87-88.

YAGITA, K. and ENDO, T. 1999. Malaria infections in Japan. Jpn. J. Infect. Dis. 52(1):20. 